terms the energy loss per millimetre-is much greater for pions, at the end of their path, than for $x$ rays. As consequence of the high linear energy transfer the biological effect, for the same radiation dose, is about twice as great with negative pions as with $x$ rays, and as a further benefit the linear energy transfer for negative pions is, until the end of their path, much the same as for $x$ rays. Consequently the possibility of radiation damage to healthy tissues traversed on the way to the tumour is further reduced, since the biological effectiveness of radiation absorbed in this region is only about half as great as for the high linear energy transfer radiation delivered to the tumour. Thirdly, it is likely that particles (such as negative pions) with a high linear energy transfer will be more effective in dealing with the hypoxic cells which are present in many tumours and are about three times as resistant to radiation as fully oxygenated cells.

For these reasons it seems that negative pions will be able to deliver radiation more satisfactorily than traditional radiotherapy to a tumour and that this radiation will be biologically more effective. Unfortunately there is no pion source in the world with enough output to test these predictions, though the Los Alamos $\pi$-Meson Production Facility now being built will give a negative pion dose rate of $100 \mathrm{rad} / \mathrm{min}$, which is adequate for radiotherapy. But the clinical merits of treatment with negative pions are still uncertain despite the attractive theoretical possibilities. Sharper localization of the delivered radiation dose is of limited value because the size and location of the tumour can seldom be accurately estimated and because tumours are seldom of regular shape but often project into other tissues. Experimental studies ${ }^{1}$ indicate that better definition of the treated volume will probably be of only marginal advantage in clinical practice. The other advantages of negative pions may be more easily assessed, since some of them are shared by fast neutrons, which also have a high linear energy transfer and should, on theoretical grounds, be more effective than $x$ rays in dealing with hypoxic cells. Within the next five years these prospects should be capable of critical appraisal as a result of the neutron radiotherapy studies now in progress at Hammersmith, Manchester, and Glasgow. If neutron radiotherapy proves to have real clinical advantages, further consideration should be given to the construction of a machine for negative pion treatment. But the cost of such a project would need to be weighed against current needs in other areas of cancer research and treatment.

${ }^{1}$ Bond, V. P., American fournal of Roentgenology, 1971, 111, 9.

\section{Clinical Judgement}

The Government has not yet announced whether the Parliamentary Commissioner's scope of inquiry will be enlarged to include complaints about the hospital service, though this was the recommendation of the House of Commons Select Committee which reported last week. ${ }^{1}$ Both the B.M.A. and the Joint Consultants Committee have made representations against the proposal, but Sir Alan Marre, who succeeded Sir Edmund Compton in April this year as Commissioner, seemed unperturbed by these medical objections when giving evidence to the committee.

The committee stated the problem clearly. "With a complaint about the failure of the ambulance to arrive or the squalid condition of the casualty department, no doctor is going to object to the Commissioner giving a ruling. The difficulty arises when a patient dies because he is treated in a certain way and people believe if he had been treated in another way he might have survived." Sir Alan's answer to that problem was that he hoped to have "a distinguished panel" available, which would decide whether the doctor's action in the particular case was something that a reasonable doctor might have done.

This is the wrong answer. If a patient or his relatives believe that he has suffered because of a doctor's error of clinical judgement, there is a remery available in the courts, which will apply long-established principles of the law of negligence. The Parliamentary Commissioner's jurisdiction does not extend to any action for which there is a remedy at law. Surely the test that should be applied is whether the complaint arises from the exercise of clinical judgement? If it does, then an assessment of the reasonableness of that judgement is a matter for the courts.

1 Second Report from the Select Committee on the Parliamentary Commissioner for Administration. London, H.M.S.O. 1971, price $80 \mathrm{p}$.

\section{The Future for Manic- depressives}

An average practice list of 2,000 people contains anything from 20 to 200 manic-depressives who will one day have a serious breakdown. Among these are the people who will at some time kill themselves if the doctor does not treat them when that time comes, for the bulk of successful suicides are manic-depressives. The correct management of such patients may be life saving. Other manic-depressive illnesses produce a crop of family or community problems-shoplifting, traffic offences, marital breakdowns, periods of heavy drinking, failure at university, even infanticide. These all demand special management apart from the use of antidepressant drugs or electric convulsion therapy and quite possibly inpatient psychiatric care. For the recovered manicdepressive there is then a further set of questions: what about marriage, or having another child, or renewing the driving licence, or getting on the permanent staff? What is the prognosis?

In spite of the name most manic-depressive people have only attacks of depression, and these attacks are often years apart. Only a few individuals have attacks of mania, either alone or sometimes paired with a depressive attack before or after. The most characteristic feature of these depressions is how they contrast with the patient's normal life and personality, how the cheerful activity of years is replaced by an all-pervading flatness or sadness, with loss of ability to enjoy or to get interested in anything, impaired power of concentration, inability to do a full day's work (sometimes any at all), worry over health, disturbed sleep with early morning waking, and the other signs of an endogenous depression. This phase usually lasts weeks or even months without much change, is only temporarily if at all lifted by human warmth or environmental change, but ends spontaneously or by the action of tricyclic antidepressants or E.C.T. Thereafter the patient is again cheerful and active, possibly for many years, when eventually another attack may strike. Often the patient can think of no reason for depression. Sometimes, too, some other member of the family 
had had a similar psychiatric illness. Not all depressions are in patients with manic-depressive psychosis, but even the true manic-depressives may have their attacks precipitated by psychological stress. But the manic-depressive concept is that certain persons in the population are liable to endogenous depression, and even they are only liable at certain times, when for internal reasons they become especially sensitive to stress.

Not all psychiatrists agree about this picture of depression. An influential group holds that depression is a continuum from neurotic reaction to deepest psychosis, ${ }^{1}$ to be understood and treated in psychological terms, and that all attempts to subdivide the patients into groups of cases of differing aetiology but with similar illnesses are mistaken in theory and practice. Those who take this view largely eschew formal diagnosis-the categorization of patients into subgroups of similar natural history and prognosis-and judge the risk of suicide or future breakdown separately for each individual they treat in terms of that individual's psychodynamics. A large group of psychiatrists, however, adopts the view taken here ${ }^{2}$ that depression comprises a mixed group of conditions. In some of them bodily factors play an important part, and it is theoretically and practically necessary to find diagnostic distinctions which separate depressives into categories with different treatments and prognoses.

The difference between these two schools of thought is partly philosophical, with echoes of the old vitalistmechanist controversy, and partly arises in a different experience of patients. Epidemiological study has shown that one practice, one region, one country, is not necessarily like another in its content of depressives - or bronchitics for that matter. The number of cases one can find per thousand persons per annum depend on the sex and age distribution of the population, the physical and human environments, and the origins of the people. But not all sufferers find their way to a doctor, nor is their true condition always recognized. What cases the family doctor notes, or the psychiatrist examines in the outpatient clinic, or the consultant sees in private practice depend on the biases of referral. A useful recent review by $\mathrm{G}$. L. Klerman ${ }^{3}$ of the whole question of diagnosis in depression draws attention to evidence of such biases in New Haven (Connecticut), where the same psychiatrists worked in general hospital, state mental hospital, and mental health centre. C. A. H. Watts, in a survey of over 16 years in a big rural practice, ${ }^{4}$ saw nearly 800 attacks of manic-depressive illness in that time (in a practice of 8,000 ), of which he sent to a psychiatric hospital 148 in depression and 15 in mania. Other doctors, less psychiatrically aware, might have done differently.

The most serious future for manic-depressives is the probability of suicide. P. Sainsbury reviewed ${ }^{5}$ a number of studies in which psychiatrists followed up their cases of manic-depressives and found that about $15 \%$ of them died by their own hand. He also explored the admittedly incomplete records of coroners' inquests and, like Watts, came to the conclusion that at least half of the suicides were in people suffering from the depression of manic-depressive psychosis. In subsequent work with B. M. Barraclough and others, ${ }^{6}$ where a full inquiry was made into 100 consecutive suicides in one area, it appeared that as many as threequarters were suffering from depressive illness at the time.

What happens to those who avoid suicide? A recent inquiry ${ }^{7}$ followed up 115 patients seen privately in St. Louis, half treated at home and half in a general hospital from 14 to 20 years ago. The sample contained about three times as many women as men, and at least one-third of the patients had had a relative in a mental hospital at some time. The great majority had only depressive attacks in the time reviewed, but 10 had some manic attacks as well, and a further five had manic attacks only, without depression, and the appearance of a manic attack made the prognosis worse. Twenty-two patients had not recovered-were unable to work or to function socially most of the time in 14 years or more-and eight of these had at least one manic attack. On the other hand, 78 had functioned well throughout the follow-up period, though not in all cases free of further attacks. Confidence in the significance of these results increases when they are seen to resemble those obtained elsewhere. For example, at the University of Oslo psychiatric department 207 patients admitted with manic-depressive illness were followed up for at least six years. ${ }^{8}$ Again about $20 \%$ were found to be essentially chronic, and the occurrence of at least one manic attack was a bad sign $(80 \%$ of the cases had depressions only). But of 149 patients who recovered completely $60 \%$ had new attacks of illness of some degree in the next six years.

For practical purposes it looks as though we would not go too far astray if we reckoned that one-fifth of our severely depressed patients would become chronic, a sixth would kill themselves, and two-thirds do fairly well. It is a reminder that much improvement in treatment is needed.

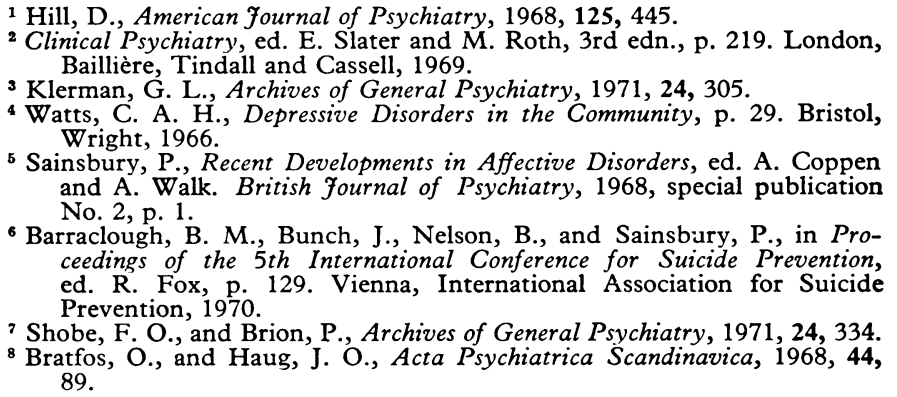

\section{A Common Language}

The spread of English as the international language of science is something that native speakers of it welcome with relief and gratitude. But in accepting the compliment we too seldom accept the obligation that ought to go with itnamely, to speak and write the language clearly. Now another sign of its increasing favour in Europe is the publication, by the Italian Surgical Society, of a new journal entirely in English. Its editor, Dr. Paride Stefanini, explains in an introduction that Italian medical practitioners have remained excluded too long from the international world of science, of which English has become the language in general use.

Everyone will wish to see his hope fulfilled that the new journal, Surgery in Italy, "will favour collaboration among scientists who in various nations dedicate their best efforts to the progress of Surgery." At the same time if the use of a common language helps to bring about, as he suggests it should, a common way of thinking, he may rest assured that nobody will be better pleased than his British readers. For many of them would echo Browning's words now inscribed on the wall of $\mathrm{Ca}$ ' Rezzonico in Venice:

Open my heart and you will see

Graved inside of it-Italy.

1. Published quarterly by Il Pensiero Scientifico, Via Panama 48, 00198 Rome 